\title{
Verrucous carcinoma of the esophagus eluding multiple sets of endoscopic biopsies and endoscopic ultrasound: A case report and review of the literature
}

\author{
Shane Devlin MD ${ }^{1}$, Vincent Falck MD FRCPC ${ }^{2}$, Stefan J Urbanski MD², Philip Mitchell MD FRCSC ${ }^{3}$, \\ Joseph Romagnuolo MD FRCPC MSC (Epid) $)^{1,4}$
}

\begin{abstract}
S Devlin, V Falck, SJ Urbanski, P Mitchell, J Romagnuolo. Verrucous carcinoma of the esophagus eluding multiple sets of endoscopic biopsies and endoscopic ultrasound: A case report and review of the literature. Can J Gastroenterol 2004;18(7):459-462.
\end{abstract}

\begin{abstract}
A 56-year-old woman was noted to have a $5 \mathrm{~cm}$ to $6 \mathrm{~cm}$ long, irregular narrowing of the distal esophagus on an upper gastrointestinal series. Initial endoscopy revealed a polypoid mass in the distal esophagus and concurrent endoscopic ultrasound revealed changes typical of inflammation but no evidence of an obvious neoplastic process. Repeated biopsies revealed only inflammation with no evidence of malignancy. Only after prolonged acid suppression did biopsies reveal verrucous carcinoma of the esophagus. The patient underwent a trans-hiatal esophagectomy and has remained well with no evidence of progression since.

Verrucous carcinoma is a rare variant of squamous cell carcinoma, taking on a papillary or warty appearance grossly. Histological diagnosis may be difficult because this tumour typically shows no highgrade dysplasia. Therefore, diagnosis can be challenging, often requiring multiple sets of endoscopic biopsies due to the overlying hyperkeratotic layer. Of the 20 cases that have been reported, this is the second to provide an endosonographic description and the first to describe a change in endoscopic appearance with acid suppression.
\end{abstract}

\section{Un carcinome verruqueux de l'œsophage se dérobant à de multiples biopsies endoscopiques et à une échographie endoscopique : Rapport de cas et analyse bibliographique}

Key Words: Endoscopic ultrasound; Esophageal cancer; Verrucous carcinoma

\begin{abstract}
Une femme de 56 ans présentait un rétrécissement irrégulier de 5 ou $6 \mathrm{~cm}$ de l'œsophage distal au transit œesogastroduodénal. L'endoscopie initiale a révélé une masse polypoïde dans l'œsophage distal, et une échographie endoscopique concomitante a révélé des changements caractéristiques d'une inflammation, sans trace de processus néoplasique évident. Des biopsies répétées n'ont révélé qu'une inflammation, sans observation de malignité. Ce n'est qu'après une suppression d'acide prolongée que les biopsies ont révélé un carcinome verruqueux de l'œsophage. La patiente a subi une oesophagectomie transhiatale et est demeurée en santé, sans trace de progression depuis.

Le carcinome verruqueux est une rare variante du carcinome spinocellulaire qui prend une nette apparence papillaire ou verruqueuse. Il peut être difficile de parvenir à un diagnostic histologique parce que d'ordinaire, la tumeur ne révèle aucune dysplasie de haut grade de malignité. Par conséquent, il peut être difficile de poser un diagnostic, et il faut souvent procéder à de multiples biopsies endoscopiques en raison de la couche hyperkératosique sus-jacente. Des 20 cas déclarés, c'est le deuxième à comporter une description endosonographique et le premier à décrire une modification de l'apparence endoscopique à la suppression d'acide.
\end{abstract}

\section{CASE PRESENTATION}

A 56-year-old woman with insulin-requiring type 2 diabetes and a half-pack per day smoking history but no history of significant alcohol use presented with anemia and epigastric discomfort in April 2001. She had no esophageal symptoms, including normal swallowing and no reflux. There was no history of gastroesophageal reflux symptoms or caustic ingestion.

Initial investigations in August 2001 included an esophagogram and upper gastrointestinal series which demonstrated a $5 \mathrm{~cm}$ to $6 \mathrm{~cm}$ long, circumferential mucosal irregularity of the distal esophagus. After referral to an esophageal surgeon, she was referred to gastroenterology (October 2001) for esophagogastroduodenoscopy (EGD) and endoscopic ultrasound (EUS) for staging of what was thought to represent an esophageal neoplasm. A nodular, circumferential mucosal abnormality was seen

in the lower esophagus and on EUS the esophageal wall was thickened at $6 \mathrm{~mm}$ (normal thickness is less than $3 \mathrm{~mm}$ ) and hyperechoic, but the outer radial edge remained smooth (Figure 1A). The wall layers were blurred, but present. Three small, paraesophageal lymph nodes were noted but they were either oval or triangular and were hyperechoic; features consistent with a benign appearance. Biopsies showed only moderate reflux esophagitis with no evidence of dysplasia or malignancy. The patient was treated with pantoprazole $40 \mathrm{mg}$ orally twice daily.

Because of a high index of suspicion, a repeat EGD was performed on October 26, 2001 that once again revealed a nodular, polypoid mass in the lower esophagus (Figure 2A). Biopsies at this time revealed only reactive epithelial changes with no evidence of malignancy. Proton pump inhibitor therapy was continued empirically pending a repeat EGD that was done on

\footnotetext{
${ }^{1}$ Division of Gastroenterology; ${ }^{2}$ Department of Pathology; and ${ }^{3}$ Department of Surgery; ${ }^{4}$ Department of Community Health Sciences,

The University of Calgary, Calgary, Alberta

Correspondence: Dr J Romagnuolo, University of Calgary Medical Clinic, 3350 Hospital Drive Northwest G-179, Calgary, Alberta T2N 4N1.

Telephone 403-210-9363, fax 403-210-9368, e-mail j.romagnuolo@ucalgary.ca

Received for publication February 26, 2004. Accepted April 21, 2004
} 


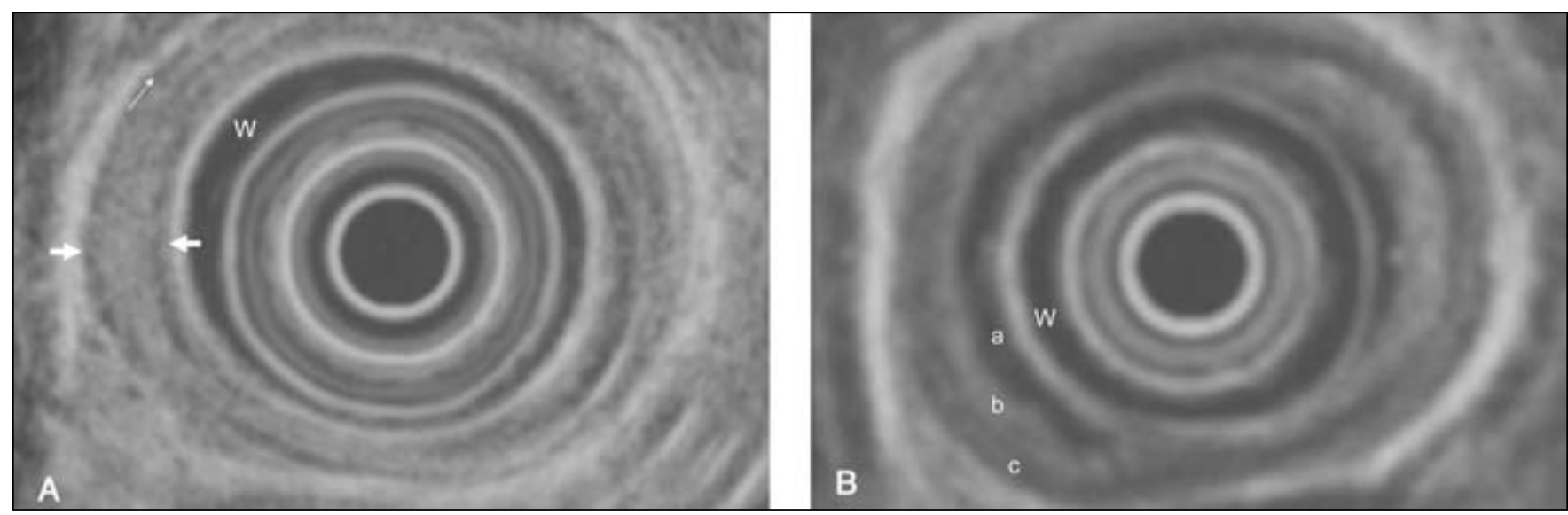

Figure 1) A Radial endoscopic ultrasound appearance of the tumour at the time of first endoscopy. Thick arrows indicate a thickened wall with blurred wall layers adjacent to the water-filled balloon (W). Parts of the muscularis propria (thin arrow) can be seen as an inconsistent dark/hypoechoic stripe. Bright hyperechoic adventitia is seen surrounding the muscularis. B Radial endoscopic ultrasound appearance of the tumour preoperatively after acid suppression. The wall layers are more well-defined. The deep mucosa (dark, hypoechoeic layer) appears thickened (a), with mild thickening of the bright/hyperechoic submucosal layer (b). The normal muscularis propria (c) layer is well seen as a dark/hypoechoic stripe split into longitudinal and circular muscle layers separated with a thin intermittent bright layer. Normal bright/hyperechoic adventitia is seen surrounding the wall. The water-filled balloon is labelled ' $W$ '

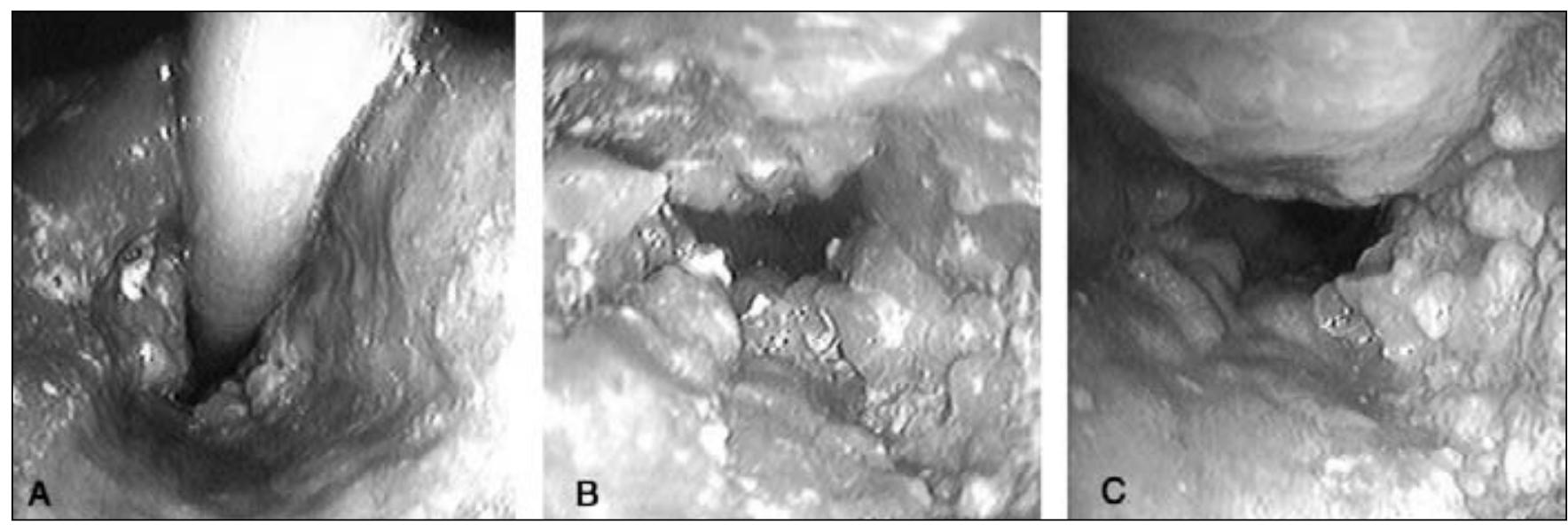

Figure 2) Endoscopic appearance of the tumour. Panel A was taken October 26, 2001; panel B was taken December 5, 2001; panel C was taken February 13, 2002 and shows the more typically described 'warty' appearance, in comparison to panels A and $\mathbf{B}$, which demonstrate a friable polypoid circumferential mass

December 5, 2001. The previously noted polypoid mass was again noted but had decreased in length from $7 \mathrm{~cm}$ to approximately $3 \mathrm{~cm}$ to $4 \mathrm{~cm}$ (Figure 2B). Repeat biopsies once again showed only changes consistent with reflux esophagitis. The proton pump inhibitor therapy was then changed to esomeprazole $40 \mathrm{mg}$ orally twice daily.

Again, due to the highly suspicious nature of the lesion, a repeat EGD was performed on February 13, 2002 that revealed a more sessile, warty mass, $5 \mathrm{~cm}$ in length in the lower esophagus (Figure 2C). Biopsies taken on this occasion were diagnosed as high-grade squamous dysplasia. A second pathologist then reviewed these biopsies and a diagnosis of in situ verrucous carcinoma of the esophagus was suggested. Immunohistochemistry was negative for the human papilloma virus (HPV).

Repeat EUS was done pre-esophagectomy on March 27, 2002 that revealed esophageal wall thickening at $5 \mathrm{~mm}$ (Figure 1B) and an $8 \mathrm{~mm} \times 3 \mathrm{~mm}$ celiac lymph node. An EUS-guided lymph node fine needle aspiration was performed, which revealed no evidence of malignant involvement. A computed tomagraphy scan of the abdomen and chest did not show any evidence of distant metastases.

On April 4, 2002 the patient underwent trans-hiatal esophagectomy complicated by a wound infection postoperatively.

The resected specimen contained a circumferential whitish tan verrucous tumour $2.7 \mathrm{~cm}$ long, located above a grossly normal gastroesophageal junction (Figure 3). Five periesophageal lymph nodes were free of tumour.

Histologically, most of the tumour was represented by low grade dysplasia, characteristic of verrucous carcinoma. These areas had been previously sampled on biopsies creating diagnostic difficulties. In the resected tumour, one could appreciate one focus of submucosal invasion with keratinization and high grade dysplasia (Figure 4). She continues to do well 14 months later, with no clinical evidence of recurrence.

\section{DISCUSSION}

Verrucous carcinoma of the esophagus is a rare variant of squamous cell carcinoma. It was first described in 1967 (1), and there are now 20 reported cases in the literature (1-15). 


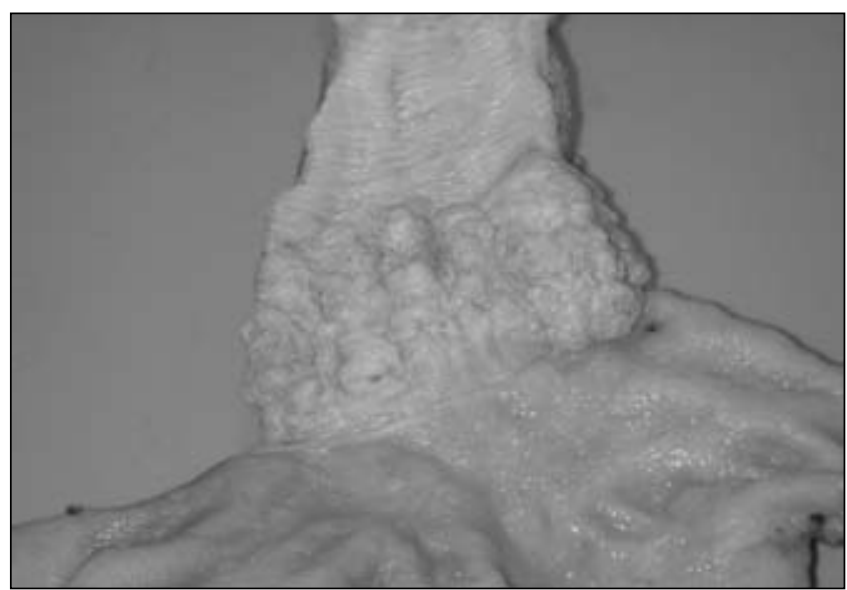

Figure 3) Gross resected specimen, highlighting the circumferential, tan, verrucous or 'warty' appearance, with a grossly normal gastroesophageal junction. (Photograph courtesy of Dr Mel Andersen)

Similar verrucous carcinomas have been reported in a variety of other locations including the oral cavity, nasal cavity, larynx, genitalia, cervix, urinary bladder and anus (16-20). Grossly, the tumour takes on a papillary or warty appearance and tends to be slow growing, often being advanced at time of diagnosis. Histologically it is well differentiated, showing hyperkeratosis and acanthosis. It typically invades as a column of neoplastic cells with an intact basement membrane in a pushing fashion rather than as discrete groups of invasive cells.

The current case is somewhat atypical in its clinical presentation, because anemia and vague epigastric discomfort were the only presenting symptoms. Dysphagia was absent in only four of the 19 previously reported patients (21\%) for whom clinical details are provided. Clinical characteristics of the previously reported cases are outlined in Table 1 . In a significant proportion of patients, symptoms were present for many months to years before diagnosis.

The diagnosis requires a high index of suspicion due to the well-differentiated and often benign appearance histologically. This is well illustrated in the current case, as 26 biopsy specimens from four sets of endoscopic biopsies were required to make a diagnosis. In 13 of the 19 previously reported cases for which clinical details are provided, the diagnosis also required more than one set of biopsies. Because one focus of high grade dysplasia was identified in the resected specimen, the question of whether one is dealing with a verrucous carcinoma or a hybrid tumour (verrucous carcinoma coexisting with keratinizing squamous cell carcinoma) arises. However, the clinical presentation, as well as the remainder of the examined tumour, showed features typical of verrucous carcinoma; therefore, we feel that it should be labeled as such.

There is no known etiology of verrucous carcinoma of the esophagus. Verrucous carcinomas of the vagina, vulva and penis are associated with HPV (21). HPV has been reported to be present in a proportion of esophageal squamous cell carcinomas (22-24). In this patient, as well as four other reported cases of verrucous carcinoma of the esophagus, no HPV was detected $(5,8,11,14)$. Alcohol use, smoking, achalasia and caustic exposure have all been implicated as risk factors for squamous cell carcinoma of the esophagus (25). It is interesting to note that 11 of the 16 patients for whom information regarding smoking status is available were smokers. Three

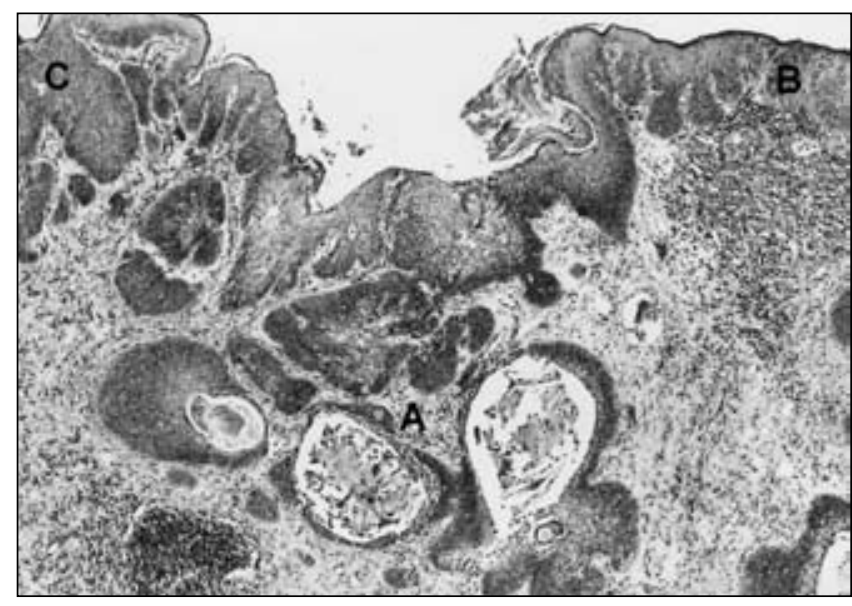

Figure 4) Extended sampling of resected tumour showed an isolated focus of submucosal invasion with high grade dysplasia and keratinization (A). Both shoulders showed features of low grade dysplastic squamous epithelium characteristic of verrucous carcinoma (B and C). (Hematoxylin and eosin stain, 40x)

\section{TABLE 1 \\ Clinical characteristics of reported cases of verrucous carcinoma of the esophagus}

Presenting symptom

Dysphagia, $14 / 19^{\star}$

Hematemesis, $2 / 19^{*}$

Location of tumour

Upper esophagus, 6

Mid-esophagus, 4

Lower esophagus, 11

Age at diagnosis (years)

Average: 61 (36-79)

Male:female

$12: 8^{*}$

Invasion present

$8 / 19^{*}$

Multiple sets of biopsies required for diagnosis

$3 / 19^{*}$

${ }^{*}$ Clinical information is not available for all 20 of the reported cases. Information presented includes characteristics of the present case report

patients had achalasia, three had remotely antecedent lye ingestion and one had an esophageal acid burn 27 years earlier. Verrucous carcinoma of the esophagus has been induced experimentally in rats after prolonged exposure to $\mathrm{N}$-methyl-Nnitrosoaniline, perhaps lending some support to the idea that chronic esophageal irritation is important in the pathogenesis of this tumour (26). This is further supported by the case reported by Kavin et al (14) demonstrating the evolution of verrucous carcinoma of the esophagus upon a background of chronic esophagitis felt to be related to lye and kerosene exposure. Our patient, however, had no history of previous or ongoing esophageal damage, despite an apparent change in endoscopic appearance with acid inhibition.

Because of histologically proven prominent inflammation in this case, an attempt was made to heal the inflammatory aspect of the lesion with empiric acid inhibition, in order to increase the probability of obtaining a more accurate noninflamed histological sample. With acid inhibition, the tumour length appeared to decrease and when esomeprazole was introduced at a dose of $80 \mathrm{mg} /$ day, the endoscopic appearance transformed from polypoid to sessile and warty (Figure 2C). Although squamous carcinoma is not classically associated with reflux esophagitis, in contrast with adenocarcinoma, acid 
reflux appears to have contributed in part to the initial polypoid endoscopic appearance. Longstanding asymptomatic acid damage to her esophagus could have played some role in the pathogenesis of her tumour, although this is purely speculative. Typical squamous carcinoma tends to occur in the upper esophagus whereas there is a propensity for verrucous carcinoma to occur in the lower esophagus (Table 1) (25). This and the hypothesized relationship to acid reflux are two features of verrucous carcinoma that bear some similarity to adenocarcinoma.

Limited comment can be made concerning the treatment of verrucous carcinoma of the esophagus due to its rarity. Nine of the 20 patients for which clinical information was provided were treated surgically, usually with esophagectomy. However, in one patient, the tumour was detected on mass screening for gastric cancer and was small enough to be resected endoscopically (12). Two patients were treated with radiotherapy due to inoperability (1) However, radiotherapy is not advocated for verrucous tumours because it has been reported to cause anaplastic transformation and lead to distant metastasis (27-29). The remaining patients either died preoperatively or were treated with supportive measures.

Although verrucous carcinoma of the esophagus tends to be present for months to years before diagnosis and appears deceptively benign histologically, the first reported cases were generally associated with a poor prognosis. Of the first 14 reported cases, the patients' survival ranged from a short number of days to months, with only two patients surviving more than one year $(1-7,9)$. The most common causes of death were respiratory failure related to esophagobronchial fistula and local recurrence. More recent case series have described a better prognosis with

\section{REFERENCES}

1. Minielly JA, Harrison EG Jr, Fontana RS, Payne WS. Verrucous squamous cell carcinoma of the esophagus. Cancer 1967;20:2078-87.

2. Meyerowitz BR, Shea LT. The natural history of squamous verrucose carcinoma of the esophagus. J Thorac Cardiovasc Surg 1971;61:646-9.

3. Parkinson AT, Haidak GL, McInerney RP. Verrucous squamous cell carcinoma of the esophagus following lye stricture. Chest 1970;57:489-92.

4. Agha FP, Weatherbee L, Sams JS. Verrucous carcinoma of the esophagus. Am J Gastroenterol 1984;79:844-9.

5. Barbier PA, Luder PJ, Wagner HE, Becker CD, Scheurer U, Ruchti C. Verrucous acanthosis - so-called verrucous carcinoma of the esophagus. Z Gastroenterol 1987;25:93-7.

6. Koerfgen HP, Husemann B, Giedl J, Hohenberger W. Verrucous carcinoma of the esophagus. Endoscopy 1988;20:326-9.

7. Jasim KA, Bateson MC. Verrucous carcinoma of the oesophagus a diagnostic problem. Histopathology 1990;17:473-5.

8. Biemond P, ten Kate FJ, van Blankenstein M. Esophageal verrucous carcinoma: Histologically a low-grade malignancy but clinically a fatal disease. J Clin Gastroenterol 1991;13:102-7.

9. Roach E, Barr G. Verrucous carcinoma of the oesophagus and achalasia. J Gastroenterol Hepatol 1993;8:107-9.

10. Garrard CL, Sheih WJ, Cohn RA, Sawyers JL. Verrucous carcinoma of the esophagus: Surgical treatment for an often fatal disease. Am Surg 1994;60:613-6.

11. Malik AB, Bidani JA, Rich HG, McCully KS. Long-term survival in a patient with verrucous carcinoma of the esophagus. Am J Gastroenterol 1996;91:1031-3.

12. Tajiri H, Muto M, Boku N, Ohtsu A, Yoshida S, Kawahara H. Verrucous carcinoma of the esophagus completely resected by endoscopy. Am J Gastroenterol 2000;95:1076-7.

13. Ereno C, Lopez JI, Loizate A, Bilbao FJ. Verrucous carcinoma of the esophagus. Endoscopy 2001;33:297.

14. Kavin H, Yaremko L, Valaitis J, Chowdhury L. Chronic esophagitis evolving to verrucous squamous cell carcinoma: Possible role of exogenous chemical carcinogens. Gastroenterol 1996;110:904-14.

15. Osborn NK, Keate RF, Trastek VF, Nguyen CC. Verrucous carcinoma of the esophagus: Clinicopathophysiologic features and treatment of a rare entity. Dig Dis Sci 2003;48:465-74. event-free survival at time of last follow-up ranging from 18 months in the current case to three years (10-12). Not surprisingly, invasion of the tumour is associated with shorter survival.

The current case is the second to provide an endosonographic description of verrucous carcinoma of the esophagus. The most common endosonographic appearance of esophageal squamous cell carcinoma is that of a focal or eccentric hypoechoic mass involving a variable number of layers, depending on the $\mathrm{T}$ stage, with or without abnormal lymph nodes. EUS imaging in this case is in keeping with what can be seen in other inflammatory processes of the esophagus, with nonspecific circumferential wall thickening and blurring of sonographic wall layers (mucosa, submucosa, muscularis propria). However, this nonspecific inflammatory appearance does not rule out tumour, because it can occur in response to early neoplasia or high-grade dysplasia. A similar EUS appearance was noted in the case reported by Osborn et al (15).

\section{CONCLUSION}

Verrucous carcinoma of the esophagus in a unique hyperkeratotic variant of squamous carcinoma which typically does not show high grade dysplasia. Its endoscopic appearance appears to be influenced by acid inhibition. Endosonographically, this tumour can take on more of an inflammatory appearance, which can be falsely reassuring. This case, and others, demonstrates the need for both an awareness of this tumour type and a high index of suspicion. Persistence and repeated mucosal biopsies, perhaps after healing of any associated esophagitis, are the keys to diagnosis.

16. Friedell HL, Rosenthal LM. The etiologic role of chewing tobacco in cancer of the mouth: report of eight cases treated with radiation. J Am Med Assoc 1941;116:2130-5.

17. Gingrass PJ, Bubrick MP, Hitchcock CR, Strom RL. Anorectal verrucose squamous carcinoma: report of two cases. Dis Colon Rectum 1978;21:120-2.

18. Kraus FT, Perezmesa C. Verrucous carcinoma. Clinical and pathologic study of 105 cases involving oral cavity, larynx and genitalia. Cancer 1966;19:26-38.

19. el-Sebai I, Sherif M, el-Bolkainy MN, Mansour MA, Ghoneim MA Verrucose squamous carcinoma of bladder. Urology 1974;4:407-10.

20. Jennings RH, Barclay DL. Verrucous carcinoma of the cervix. Cancer 1972;30:430-4.

21. Hacker NF, Eifel P, Mcguire W, et al. Vulva. In: Hoskins WJ, Perez CA, Young RC, eds. Priniples and Practices of Gynecologic Oncology. Philadelphia: JB Lippincott, 1992:537-66.

22. Poljak M, Cerar A. Human papillomavirus type 16 DNA in oesophageal squamous cell carcinoma. Anticancer Res 1993;13:2113-6.

23. Chen B, Yin H, Dhurandhar N. Detection of human papillomavirus DNA in esophageal squamous cell carcinoma by the polymerase chain reaction using consensus primers. Hum Pathol 1994;25:920-3.

24. Togawa K, Jaskiewicz K, Takahashi H, Meltzer SJ, Rustgi AK. Human papillomavirus DNA sequences in esophagus squamous cell carcinoma. Gastroenterology 1994;107:128-36.

25. Ginsberg G, Fleischer D. Esophageal tumors. In: Feldman M Friedman L, Sleisenger M, eds. Gastrointestinal and Liver Disease Pathyphysiology/Diagnosis/Management. Philadelphia: Saunders, 2002;1:647-71.

26. Napalkov NP, Pozharisski KM. Morphogenesis of experimental tumours of the esophagus. J Natl Cancer Inst 1969;42:927-40.

27. Ferlito A, Recher G. Ackerman's tumour (verrucous carcinomas) of the larynx. Cancer 1980;464:1617.

28. Perez CA, Kraus FT, Evans JC, Powers WE. Anaplastic transformation in verrucous carcinoma of the oral cavity after radiation therapy. Radiology 1966;86:108-15.

29. Proffitt SD, Spooner TR, Kosek JC. Origin of undifferentiated neoplasm from verrucous epidermal carcinoma of oral cavity following irradiation. Cancer 1970;26:389-93. 


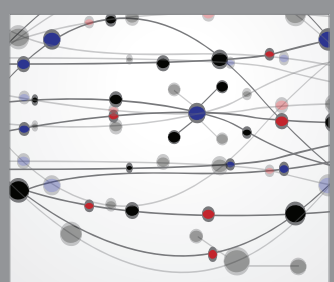

The Scientific World Journal
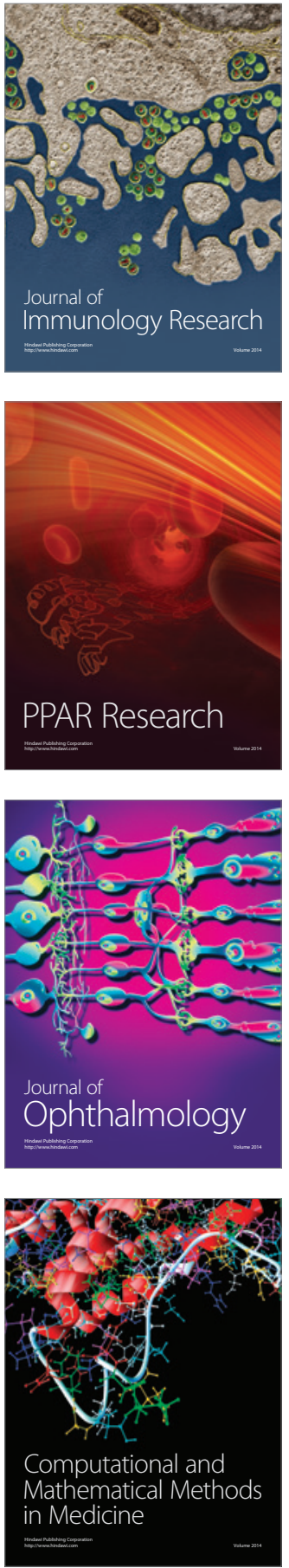

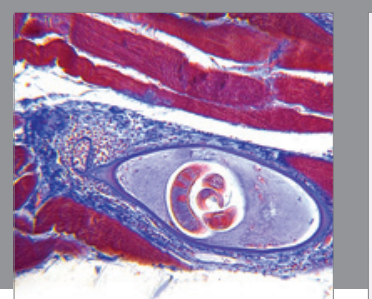

Gastroenterology Research and Practice

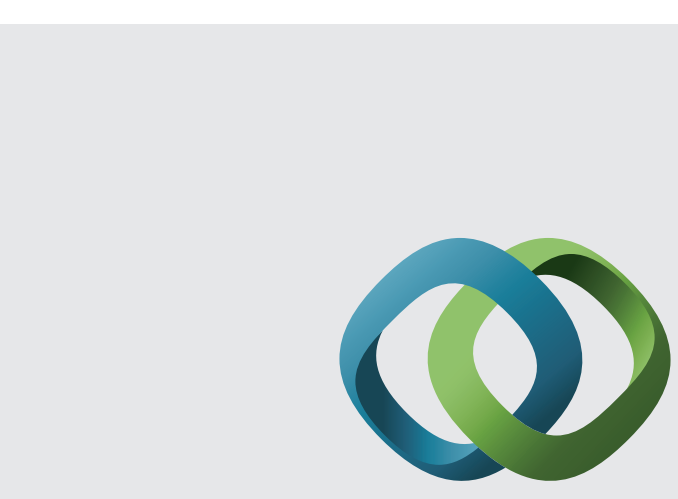

\section{Hindawi}

Submit your manuscripts at

http://www.hindawi.com
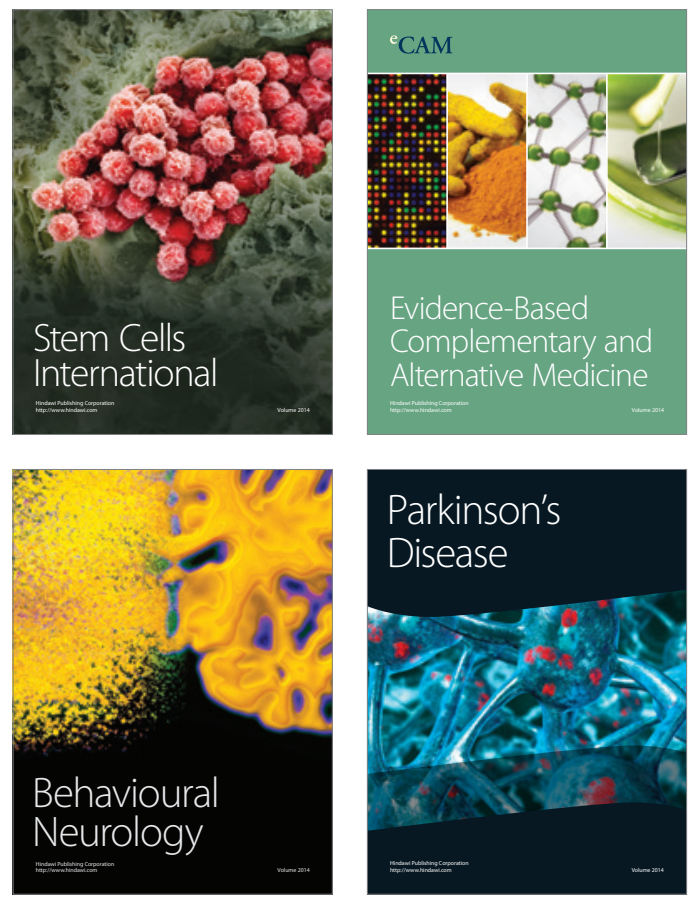
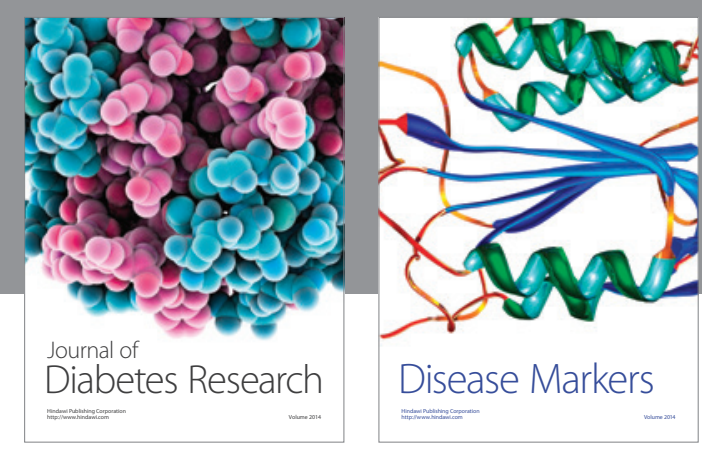

Disease Markers
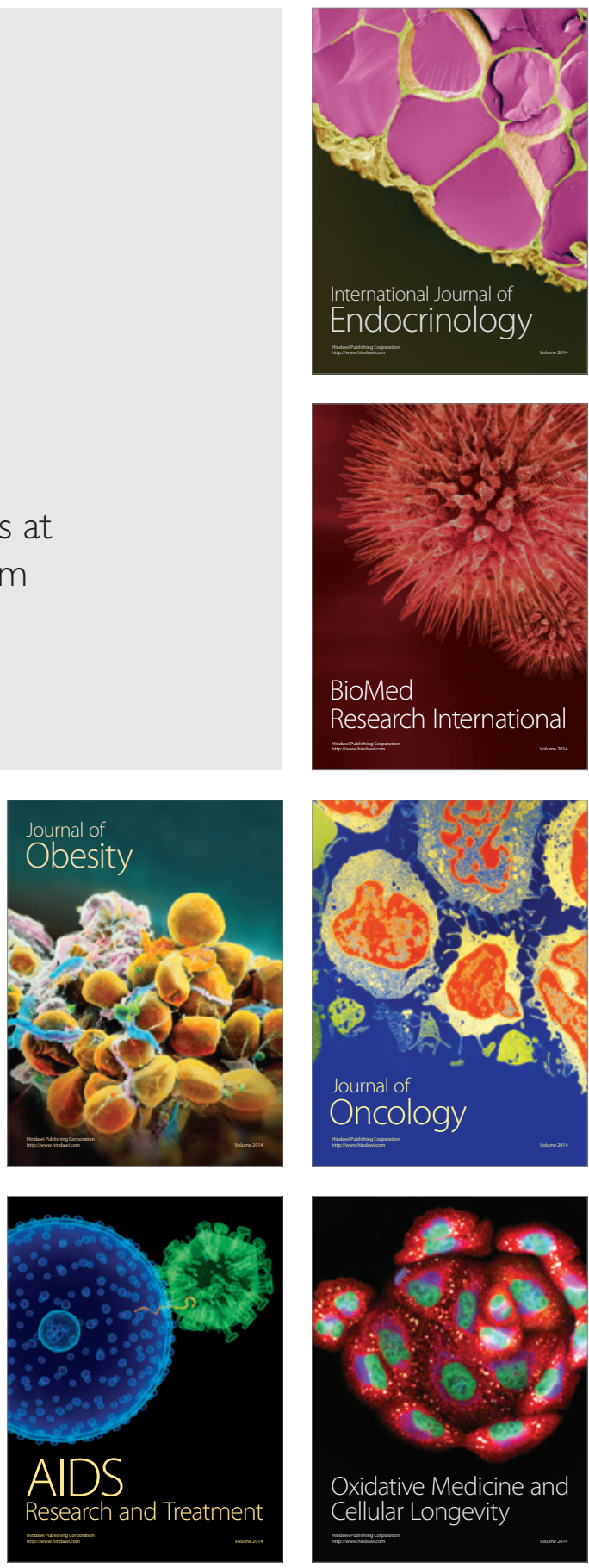